\title{
Entrevista com Antonio Carlile Holanda Lavor: é preciso investir em pesquisas para aprender como orientar as famílias contra a Covid-19
}

\author{
Interview with Antonio Carlile Holanda Lavor: we must invest \\ in research to learn how to guide families against COVID-19
}

Antonio Carlile Holanda Lavor (https://orcid.org/0000-0002-7548-4332) ${ }^{1}$

Entrevistado por: Ivana Cristina de Holanda Cunha Barreto, Luiz Odorico Monteiro de Andrade e Vanira Matos Pessoa

${ }^{1}$ Diretor da Fundação Oswaldo Cruz no Ceará. Fortaleza CE Brasil.

carlile.lavor@fiocruz.br

\begin{abstract}
In this interview, public health physician Antônio Carlile Holanda Lavor with 57-year career and long and broad experience in the Brazilian Unified Health System (SUS) management, especially in primary health care, talks about his management at the head of the Oswaldo Cruz Foundation unit in Ceará (Fiocruz-CE), from 2008 to the present moment. Known internationally for institutionalizing the Health Worker Program in Ceará in 1987, he discusses the process of implementing Fiocruz-CE and the role of research in guiding the work of the Family Health Strategy during the COVID-19 pandemic.

Key words Primary Health Care, Family Health Strategy, Community health worker, Unified Health System
\end{abstract}

Resumo Nesta entrevista, Antônio Carlile Holanda Lavor, médico sanitarista, com 57 anos de carreira, longa e ampla experiência na gestão do Sistema Único de Saúde (SUS), em especial na atenção primária à saúde, fala sobre sua gestão a frente da unidade da Fundação Oswaldo Cruz no Ceará (Fiocruz-CE), a partir de 2008 até o momento atual. Conhecido internacionalmente por haver institucionalizado o Programa Agentes de Saúde no Ceará em 1987, ele discute sobre o processo de implantação da Fiocruz-CE e o papel da pesquisa na orientação do trabalho da Estratégia Saúde da Família durante a pandemia de Covid-19.

Palavras-chave Atenção Primária à Saúde, Estratégia Saúde da Família, Agente Comunitário de Saúde, Sistema Único de Saúde 
Ivana Barreto - Carlile, até julho de 2008, você havia construído uma trajetória de $\mathbf{4 4}$ anos de trabalho em educação, por sua atuação como professor na Universidade de Brasília, e em políticas públicas, principalmente na Atenção Primária à Saúde (APS). Inclusive em 2007, e no primeiro semestre de 2008, esteve em Angola, como consultor do UNICEF, para apoiar o país na implantação dos Agentes Comunitários de Saúde (ACS). Como foi, nesse contexto, assumir a direção da Fiocruz Ceará?

Carlile Lavor - Eu e a Miria [Miria Campos Lavor, esposa e companheira de trabalho] ${ }^{1}$ chegamos da África em maio. Eu animado ainda para voltar para a África, mas em junho a Míria adoeceu gravemente de uma meningite, ficou dez dias em coma e aí estava saindo do coma já no início de julho. Finalzinho de junho o Odorico foi lá em casa [Luiz Odorico Monteiro de Andrade, à época professor da Faculdade de Medicina da UFC em Sobral e secretário municipal de saúde de Fortaleza] e disse: estamos criando aqui a Fiocruz e faz um ano e meio já e a gente não consegue avançar, precisamos de alguém que lidere o processo. O governador Cid quer saber se você aceita assumir a direção da comissão para implantar a Fiocruz Ceará. Eu aceitei.

Odorico Monteiro - Em 2008, o presidente da Fiocruz era Paulo Buss e José Gomes Temporão era ministro da Saúde. Eu provoquei afirmando que estava na hora de uma pessoa coordenar o grupo de implantação da Fiocruz Ceará. Aí eu disse a ele: olha, tem que ser uma pessoa que dialogue com as universidades, as esferas de governo e a sociedade em geral. Aí ele disse: você tem o nome? Respondi: é o Carlile Lavor, se você autorizar faço o convite. Ele autorizou e sugeriu organizar uma reunião no Palácio da Abolição para apresentar o Carlile. Foi quando eu fiz o convite e você aceitou.

Odorico Monteiro - Quando é que você internalizou a proposta da Fiocruz no Ceará?

Carlile Lavor - Quando você me fez a proposta, já estava sendo discutida há um ano e meio. O Decreto $29.342^{1}$ trazia muito claro o que era a Fiocruz e duas coisas para mim foram importantes demais. Primeiro, trata-se de um projeto para melhorar a indústria e a riqueza do Ceará e do Nordeste, a implantação de um polo industrial, ou seja, trazer oportunidades de trabalho e melhoria de renda para a população, além de for- talecer o Brasil como nação autônoma tecnologicamente. A segunda motivação era o Saúde da Família, estratégia em que trabalhei a vida toda. Então, são dois pontos: um que eu sabia bem e outro que eu não sabia nada, porém compreendia que era importante. Então, abracei inteiramente o projeto e, digo, nós temos que obedecer a esse Decreto e, nesses 12 anos, toda hora estou com este Decreto na mão porque considero que traz um direcionamento essencial. Vocês [Odorico e outros membros do $1^{\circ}$ Comitê Estadual para implantação da Fiocruz] passaram um ano e meio discutindo, de 2006 a junho de 2008.

Odorico Monteiro - O detalhe mais importante era que tínhamos convencido o Cid Ferreira Gomes ainda na campanha [para governador] sobre a importância de criar um polo de inovação tecnológica em saúde, ou seja, a Fiocruz tinha que ser âncora desse polo. Nós queríamos que a Fiocruz do Ceará fosse um dos polos de referência nacional em Saúde da Família. Quanto à definição sobre a biotecnologia, a gente trabalhava com o Odorico de Moraes [professor da UFC] e ele apresentava o Núcleo de Pesquisa e Desenvolvimento de Medicamentos da UFC como um centro de referência para a indústria de medicamentos. Além disso, havia a história do Abreu Matos na pesquisa em fitoterapia, então adotamos o domínio da biotecnologia para desenvolvimento de medicamentos como uma linha contemporânea e complementar às linhas de pesquisa e desenvolvimento tecnológico já existentes no Ceará.

Carlile Lavor - A primeira comissão dedicada à implantação do Polo Tecnológico e Industrial da Saúde no Ceará foi um desafio para mim, pois ainda não havia acumulado experiência no assunto, mas em relação à APS, eu tinha clareza que haveríamos de formar pesquisadores e professores nesta área, para o desenvolvimento de pesquisas em Atenção Primária à Saúde (APS) nas universidades, pois havia pesquisas em quantidade nos hospitais, mas nada na Estratégia Saúde da Família (ESF). Então, na primeira reunião do Comitê de Implantação da Fiocruz Ceará, propus a criação da Pós-Graduação em Saúde da Família. E em relação à indústria, fui conversar com a Federação das Indústrias (FIEC) e depois com a Agência de Desenvolvimento do Estado do Ceará (ADECE). Durante o primeiro concurso, eu e o Dr. Paulo Gadelha, decidimos selecionar três pesquisadores para a linha de pesquisa em Saúde da Família e três pesquisadores para servir de base para o Polo Industrial e Tecnológico da Saúde, es- 
pecificamente pesquisadores em Bioinformática. Também selecionamos um servidor para a parte administrativa. Nos próximos concursos fortalecemos as duas áreas. Daí os três pesquisadores foram importantes, quer dizer, você [Odorico], a Vanira e a Anya Pimentel. No concurso de 2014 foram integrados os pesquisadores Sharmênia Nuto, Roberto Wagner e Ivana Barreto. Na área da Biotecnologia houve transferências de outras unidades para o Ceará, como a Carla Celedônio e o Roberto Nicolete. Recebemos, também, o médico psiquiatra e pesquisador que veio transferido da Fiocruz Amazonas, Maximiliano Ponte. Nos primeiros meses após assumir a direção da Fiocruz no Ceará, me dediquei a conhecer bem a Fiocruz nacional e me encantei com sua grandeza e a diversidade das organizações que a compõem, com as linhas de pesquisa que a constituem. Para $\mathrm{mim}$, o roteiro a seguir era o mesmo daquele que resultou no Decreto 29.342, da criação da Fiocruz no Ceará. Nós temos que trabalhar nesses dois objetivos, logo nunca me desviei deles. Agora como implementar na indústria, ainda estamos quebrando a cabeça e ainda bem que agora, você [Odorico] está responsável por isso, desenvolver esse distrito de inovação. Quando fui à Federação das Indústrias eu disse: nós vamos fazer a indústria no Ceará e não sei nada, como é que a gente faz? Procurei também a ADECE, onde encontrei o Eduardo Diogo e fui com ele até Anápolis, onde tem uma indústria importante de medicamentos genéricos. Então ele se animou em instituir a Câmara de Saúde da ADECE e foi importante durante algum tempo essa discussão. E agora está na sua responsabilidade [Odorico] como é que a gente vai desenvolver esse distrito de inovação, desafiador, porque precisa conectar com redes de inovação e investimento em tecnologia da saúde.

Odorico Monteiro - Obrigado Carlile, estamos nos esforçando para fortalecer a Câmara de Inovação e Empreendedorismo da Fiocruz Ceará, embora não esteja sendo fácil nesse contexto de Pandemia. Sobre a implantação da Fiocruz Ceará, fale um pouco como é que foram a concepção do desenho arquitetônico e construção?

Carlile Lavor - Inicialmente, procurei conhecer bem a Fiocruz nacional para entender o que nós iríamos construir aqui, e a cada viagem ia conhecendo as pessoas, as diversas unidades técnico-científicas que a constituem, seus objetivos e domínios de produção de conhecimento e tecnologia, o que era a Escola Nacional de Saúde Pública (ENSP), o que eram Bio-Manguinhos e
Farmanguinhos. Visitei também as unidades regionais. Paulo Gadelha sempre foi um entusiasta da expansão nacional da Fiocruz. O que construímos aqui partiu muito das propostas e concepções da Presidência da fundação. Gadelha tinha um arquiteto espetacular, Leonardo Lacerda. Então, o único palpite que dei no projeto foi no térreo do prédio de gestão. Uma definição que participei foi a de que um dos prédios tivesse uma biblioteca aberta a qualquer profissional; também fiz questão de uma recepção que atenda bem as pessoas e tenha uma sala de exposição para os visitantes compreenderem o que é a Fiocruz. Eu mesmo levei um tempo para compreender a Fiocruz porque cada prédio tem uma uma organização diferente. Farmanguinhos, por exemplo, não tem nada a ver com o Instituto Oswaldo Cruz (IOC), nem com o Instituto Nacional de Controle de Qualidade em Saúde (INCQS), e nem com o Bio (Instituto Bio-Manguinhos), cada um é um mundo. Então eu disse, quero um lugar onde a gente chame de Fiocruz, as pessoas cheguem e saibam que aqui é a Fiocruz; um lugar que tenha quem as receba bem. Com essa ideia de ter a indústria, sempre achei que era importante ter alguém que pudesse orientar nesse intento. Pois, se chega um industrial e quer saber alguma coisa, precisa ter alguém que ajude essa pessoa a entrar na Fiocruz, que oriente sobre produtos e patentes. Então, foi o palpite que eu dei, e que eles aceitaram. Eu "quebrei a cabeça" para desapropriar o terreno. Por diversas vezes, fui na Procuradoria para resolver isso. Não é fácil! A pessoa está morando ali, a vida toda, e nós tínhamos que convencê-la a sair. Conversamos com as famílias e saíram tranquilamente, sem problema algum. $\mathrm{O}$ arquiteto era espetacular e a ideia foi contratar um grupo daqui que gostei muito e confiei inteiramente. Então, meu trabalho era apoiar, fazer seleção. O Estado tinha que ceder o terreno para a gente avançar. Não adiantava ser verbalmente, pois tinha que ser documentado. Está cedido para Fiocruz e, a partir daí encaminhar as licenças para poder encaminhar. A Agência de Desenvolvimento do Ceará (ADECE) teve um papel importante neste processo. Consideramos importante Eusébio reconhecer o projeto da Fiocruz como relevante para o município, e ajudar a suprir a energia que precisaríamos, além da água, esgoto etc. Esse foi o meu grande trabalho em relação ao projeto além de acompanhar de perto cada passo. Também sempre mantivemos um bom relacionamento com o Governo do Ceará para que apoiasse a implantação da Fiocruz, cultivando um relacionamento com a Fiocruz na- 
cional. Vejam, o único governador que foi para posse do presidente Paulo Gadelha foi o Cid Gomes. Assim também como o único governador que foi para a posse da presidente Nísia Trindade foi o Camilo Santana. Os recursos que conseguimos no ano passado para equipar o prédio de pesquisa da Fiocruz Ceará foi com o Camilo, com a bancada federal do Ceará, que garantiram junto ao orçamento federal. Outra ação importante foi manter sempre um bom relacionamento com os reitores das universidades do Ceará.

Odorico Monteiro - Em todas as reuniões os reitores participavam e isso foi muito importante. $\mathrm{O}$ Ceará tem cinco nucleadoras da RENASF [Rede Nordeste de Formação em Saúde da Família] e isso é um ativo, um patrimônio importante.

Carlile Lavor - A UVA [Universidade do Vale do Acaraú] até me elegeu como doutor honoris causa e agora a Urca [Universidade Regional do Cariri] também. Então me reconhecem como uma pessoa que ajudou na construção da RENASF e na integração da Fiocruz com as universidades do Ceará. Hoje, nossos pesquisadores da Biotecnologia e Bioinformática participam de Doutorados da UFC, da UECE, trabalhando com o IFCE [Instituto Federal do Ceará]. Então, a Carla, o Gilvan, todos participam de doutorados nas outras instituições, porque têm pesquisas complementares. A UNIFOR [Universidade de Fortaleza] foi importante para ajudar, e todas as universidades ajudaram na implantação da Fiocruz no Ceará. A Urca e a UVA apoiaram as turmas da RENASF e é importante demais você formar quatrocentos mestres em Saúde da Família. Somente trabalhando em rede com as instituições que compõem a RENASF, conseguimos alcançar esse resultado.

Odorico Monteiro - Isso é um ativo grande, Carlile. Infelizmente a gente está vivendo uma certa dormência pela conjuntura da pandemia, mas na hora que você tiver uma capacidade de ativação desses mestres e doutores, aí vai ser uma coisa fantástica.

Ivana Barreto - Carlile, trazendo nossa entrevista para o contexto atual, neste momento de pandemia, como é que você vê a ação da ESF e do ACS no enfrentamento desta calamidade? $O$ que é e o que poderia ser?

Carlile Lavor - Penso que a Secretaria de Saúde do Estado focou muito em providenciar a ampliação de leitos hospitalares e de UTI, e traba- lhou pouco o enfrentamento da pandemia pelas equipes de saúde da família. Estamos começando com a Secretarias Municipais de Saúde do Eusébio, Itaitinga, Aquiraz e Tauá um projeto de apoio institucional, em que orientamos o trabalho da ESF e, particularmente, do agente de saúde no enfrentamento da COVID-19. Então, você identificou o primeiro sintoma, diagnosticou COVID, como proceder na organização da família e da casa, para cuidar desse paciente e prevenir a transmissão domiciliar e extradomiciliar? Um indivíduo que não está sentindo nada ou tendo poucos sintomas precisa ser acompanhado para garantir o isolamento. Essa primeira experiência em que vocês, Odorico e Vanira, já estão participando, nessa história de criar rotinas para que a ESF possa orientar o isolamento domiciliar, pois as equipes ainda não dominam. Conseguimos fazer um grande programa materno-infantil no passado porque eu tinha experiência acumulada em saúde infantil da Universidade de Brasileira, e tínhamos um grupo importante de Pediatras com visão de saúde pública no Hospital Infantil Alberto Sabin, liderados pela Dra. Anamaria Cavalcante, que participou intensamente do processo. Esse grupo soube criar protocolos de cuidado com as crianças na APS, que foram compartilhados com os agentes de saúde. Precisamos compreender que os ACS não são graduados, então cabe à equipe de saúde criar estratégias de educação permanente para que eles possam ajudar na resolução dos problemas.

Ivana Barreto - Falando sobre a montagem da Equipe de Saúde da Família, quando não só veio médico mas também mais enfermeiros. A gente tinha uma proporção que era um enfermeiro para cada vinte agentes de saúde e, com a Estratégia Saúde da Família, a proporção ficou em um enfermeiro para seis e até dez agentes de saúde, mais um médico para trabalhar junto. Como a implantação da Equipe de Saúde da Família repercutiu no trabalho dos ACS e na APS?

Carlile Lavor - No começo foi muito bom porque a Secretaria de Saúde do Estado coordenou a implantação da ESF. Teve Quixadá, Jucás, Beberibe, Iguatu, cidades para serem implantadas a ESF. A Inês [Amaral] foi quem assumiu essa coordenação, orientando o que o médico ou enfermeiro tinham que fazer. No que só tinha uma enfermeira, passou a ter três ou quatro, mas dentro do programa do ACS; e o Saúde da Família foi implantado com a coordenação do Estado, logo foi ótimo, muito bom. Depois a coordenação es- 
tadual da ESF desapareceu. Daí cada município ia inventando o seu programa, tá certo? E vocês [Odorico e Ivana] estavam muito preocupados com Quixadá e depois com Sobral, logo foi importantíssimo porque montaram um exemplo de como fazer nestes locais, mas no resto do Estado isso ficou solto. Depois que a Inês saiu, foi desaparecendo o programa do ACS e da ESF, pois era um programa que atuava só na Secretaria Municipal de Saúde. Claro, aonde havia um secretário bom, ia lá aprender com Sobral, ou com Beberibe, ou Iguatu e Jucás. Então íamos mostrando, embora sejam 184 municípios no Ceará. Na gestão de Jurandi [Frutuoso, ex-secretário de Saúde do Ceará], a importância ficou na Escola [Escola de Saúde Pública do Ceará], com o Curso Técnico de ACS. Houve um impulso grande para o programa, mas não como Secretaria. Depois acabou-se, e não houve mais nem programa de ACS e nem da ESF na Secretaria Estadual.

Ivana Barreto - Penso que agora que a ESF e o ACS podem exercer um papel fundamental na pandemia, desde que entendam realmente da transmissão da doença, do período de incubação, da necessidades de quarentena, do período de transmissão, dos testes, quer dizer, eles precisam passar a dominar isso para poder atuar, como o Josete [Tavares, secretário municipal de Saúde do Eusébio] está fazendo em seu município.

Carlile Lavor - É importante documentar cientificamente como é que se faz. Por que hoje se você me perguntar como é que faz o isolamento numa casa pequena com seis pessoas eu não sei dizer. Então, por isso a necessidade da pesquisa. Estamos com seis mestrandos, pesquisadores e mais outras pessoas, na busca e pesquisa de como é possível isolar. A Patrícia [Aguiar, prefeita de Tauá] já pensou em alugar uma casa ou hotel em Tauá. Temos que observar a realidade em cada município. Hoje, se me perguntarem como eu sabia que soro oral era importante, que vacina era importante, que acompanhar a criança para não ficar desnutrida era importante, vou explicar, mas não sei como é que faz isolamento na situação de vida de nossas comunidades vulneráveis. Por isso vejo na pesquisa uma forma de aprender e orientar a Secretaria de Estado. Mostrar com dados que em tal município conseguimos diminuir o número de casos na medida em que a gente começou a isolar. Essa linha de pesquisa do Saúde da Família que começamos na Fiocruz Ceará agora precisa atender uma necessidade urgente, que é a pan- demia. Os pesquisadores do Saúde da Família e da Fiocruz não podem ficar alheios a esse tema. Então o pessoal do laboratório está trabalhando nas pesquisas, mas e o Saúde da Família? Qual é o papel dessa linha de pesquisa na pandemia? Penso que fortalecer esse grupo de pesquisa para ver como é que aprende a fazer isolamento vai servir para essa doença e outras que vão aparecer.

Vanira Pessoa - As pessoas têm falado muito do mundo pós-pandemia. Mas eu ainda não enxergo o pós não, vejo é o presente em que muita gente está morrendo e a APS totalmente assim desconsiderada pelo Sistema de Saúde. Como é que vamos conseguir que a APS entre no cuidado e nas ações, na promoção, na prevenção e na gestão da pandemia?

Carlile Lavor - Temos que aprender. É isso que estou pedindo a vocês [pesquisadores] junto com os municípios. Por que vocês têm a metodologia e eles lá, a mão-de-obra. Agora qual é a metodologia para aprender a fazer isso? Temos que fornecer para eles uma metodologia científica, como é que se faz um trabalho científico, como coletar e analisar os dados, como aprovar na comissão de ética. Eles têm que aprender a ser cientistas, pois essa é a ideia, que o trabalhador da saúde da família seja um cientista e contribua com a inovação. Aí precisa ter vocês para ajudar a formar esses inovadores. Como é que eu convenço o indivíduo a lavar as mãos não sei quantas vezes por dia? Isso é importante porque ele nunca viu um vírus e como é que vai acreditar que esse bicho está saindo do seu nariz e indo para o outro. Cinco pessoas tiveram contato com um infectado e só um adoeceu. Como explicar essa transmissão? Pois é difícil para a pessoa entender. Será que não foi porque ele não reza direito? Se fosse sarampo seria mais fácil de entender por que passava de um para o outro e todos na casa pegavam cólera, mas aqui [na Pandemia de COVID-19] uns pegam a doença e outros não. Por isso estou insistindo para que vocês realmente ensinem essas pessoas a fazer a pesquisa, para entenderem como orientar uma família a isolar e como o agente de saúde trabalha essa questão. $\mathrm{O}$ agente de saúde sabia conversar. Hoje eu não sei como é que está essa capacidade de conversa deles. Precisamos convencer secretários, médicos, governador, todo mundo. Por enquanto, só se fala em isolamento, UTI, leito hospitalar, mas não estou vendo ninguém falar como é que vai na casa das pessoas orientá-las, e a ESF é fundamental nesse trabalho. 


\section{Agradecimentos}

À Sheila Pires Raquel que revisou o texto da entrevista em português.

\section{Referências}

1. Santana JP, Castro JL. Os sanitaristas de Jucás e o agente de saúde - entrevista com Antonio Carlile Holanda Lavor e Miria Campos Lavor. Natal: Seminare Editora; 2016 [acessado 2021 mar 31]. Disponível em: https:// www.arca.fiocruz.br/bitstream/icict/39186/2/Os\%20 sanitaristas\%20de $\% 20 \mathrm{Juc} \%$ c3\%a1s\%20e\%20os\%20 agentes $\% 20 \mathrm{de} \% 20$ sa $\%$ c3\%bade.pdf.

2. Ceará. Secretaria de Planejamento. Diário Oficial do Estado do Ceará. Decreto 29.342. Decreto de Criação do Comitê Estadual para implantação da Unidade Avançada da Fiocruz no Estado do Ceará. Fortaleza, 02 de julho de 2008. Fortaleza: SES-CE; 2008.

Artigo apresentado em 07/08/2020

Aprovado em 20/02/2021

Versão final apresentada em 22/02/2021

Editores-chefes: Romeu Gomes, Antônio Augusto Moura da Silva 